\title{
Court backs critic of Italian jobs “carve-up’
}

Munich. In a decision widely seen as a blow to the traditional power of 'old-boy networks' in Italian universities, a Genoan researcher has successfully challenged the results of a nationwide recruitment examination held to recommend the appointment of individuals to full professor.

Gian Franco Gaetani of the University of Genoa Medical School was rejected in 1988 by one of the 300 committees set up in that year to make new university appointments under Italy's nationwide centralized competition, known as the concorso.

Gaetani complained to an administrative court, claiming that the proper procedures for assessing candidates were not followed, and that the committee that refused him promotion failed to give adequate weight to his scientific achievements. Five years later, his complaints have been upheld, and each of the five appointments made by the committee have been declared null and void.

The decision has been welcomed by many Italian scientists, who have been campaigning to end the country's unpopular system of academic promotion. They claim that this system is often manipulated by the country's academic élite, accusing it of 'cronyism' and of using the appointments process to exchange favours.

Openings for professorships, assistant professorships and associate professorships are not advertised by universities in Italy, but are offered through the concorso, which

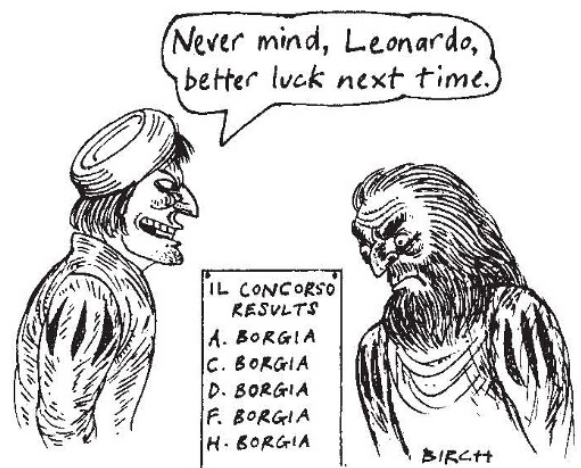

takes place every four or five years. More than 10,000 applicants were considered in the 1988 competition; by law, each should have been assessed on the basis of written applications alone listing his or her scientific achievements, including publications and service on international committees.

In November 1989, the haematology committee recommended the appointment of five candidates. But Gaetani subsequently showed that their track records, based on indices of the impact of scientific publications listed in the Science Citation Index, were lower than those of four of the ten losers (see Nature 353, 10; 1991).

The court has now declared that the five appointments are invalid, arguing that the committee failed to distinguish the precise contributions made by candidates to collaborative papers whose authors also included a member of the committee.

The court did not try to assess the scientific achievements of individuals themselves. But it did decide that the committee had been unfairly selective in its use of information from applicants. (Gaetani had claimed that his membership of important international scientific committees was ignored.)

This is the first time all the decisions of a particular committee have been declared invalid. Forty individuals have bought cases against the 1988 concorso, but so far only Gaetani has won; seven cases have been dismissed, and the remainder are pending.

The five professors promoted on the recommendations of the haematology committee now return to their former rankings, while the committee decides whether to appeal to a higher court. If the administra-

tive's court's verdict stands, the posts will be reopened through national competition.

As the committee has a year to decide whether to appeal, the promotions will probably miss the round of the concorso now being evaluated.

The haematology committee has another problem. When it was set up for the current concorso, it included some of the first recent appointees whose status as full professor has been removed. Rather than risk a second challenge to the validity of its decisions, the whole committee has been dissolved, and will be reappointed later in the year.

Changes in the whole promotions systems to Italian universities are under discussion. But unless they are introduced in the near future, the five appointments will have to wait until the next concorso, which will not take place for several years.

Alison Abbott

\section{WHO widens focus of AIDS research}

Paris. The emphasis of AIDS research on therapeutic antiviral drugs designed to attack the late stage of the human immunodeficiency virus (HIV) in infected persons produces exciting science; but it may not be the most effective way to avert an AIDS epidemic.

This was the underlying message of the decision last week by the World Health Organization (WHO) to support research into foams and creams designed to inactivate HIV in a woman's vagina.

WHO said that vaginal microbicides could revolutionize efforts to prevent heterosexual transmission of HIV by protecting women, especially in developing countries, who cannot ensure that their sexual partners use a condom.

Michael Merson, executive director of WHO's Global Programme on AIDS, said the condom remained the main defence. But with two women infected with HIV every minute, "we need a new method for women to protect themselves".

Rudi Pauwels from the Rega Institute for Medical Research in Belgium welcomed the organization's commitment to an area that he said had been neglected by mainstream antiviral AIDS research. "We have been focusing on the infected person, whereas the epidemiological data tells us we should be looking at how to prevent it," Pauwels said. "I'm not saying that we should drop vaccine research and related activities, but we need to look at all the options."

Prospects for progress towards a vaginal microbicide are uncertain. There is some evidence that existing spermicides, such as the macrogel ether nonoxynol $9(\mathrm{~N}-9)$, which has been used for more than 40 years, inhibit HIV in vitro. But Pauwels said that not enough is known about the effect of viricides have on genital transmission of HIV.

Joep Lange, head of clinical research with the WHO's Global Programme on AIDS, admitted that the concept may be flawed. "But it's worth a try," he said.

Certainly, the prerequisites for a safe topical preparation may be less stringent than for a systemic drug. Potential candidates include polyanions, such as dextran sulphate, and other inhibitors of virus adsorption/fusion. The WHO also believes that promising antivirals abandoned because of problems of bioavailability or toxicity may be suitable for vaginal preparations.

Lange said the WHO's commitment would encourage research into the use of topical preparations. The WHO would also stimulate the interest of companies by carrying out and paying for clinical trials.

According to Lange, the WHO label would lend credibility to such trials. He said that many developing countries are increasingly worried about being exploited by pharmaceutical companies trying to dump products, or entrepreneurs marketing dubious wonder-cures.

Lange also emphasized that all safety tests on vaginal microbicides would be carried out first in low-risk populations in industrialized countries. Some companies have tested existing spermicides for HIV-inhibition in high-risk populations in Kenya and Senegal, only to discover that they caused vaginal lesions. The treatment may thus have inadvertently but unethically - exposed subjects to increased risk of HIV infection.

Declan Butler 